\title{
Текстовая пунктуация поэзии шестидесятников: когнитивно- дискурсивный и коммуникативно- прагматический аспекты
}

Ключевые слова: пунктуация, метаграфемика, пунктуационный знак, текст, поэзия. Key words: punctuation, metagraphemics, punctuation mark, text, poetry.

\begin{abstract}
The article analyses the notions "text punctuation" and "metagraphemics". Texts by B. Akhmadulina, A. Voznesensky, Y. Yevtushenko, R. Rozhdestvensky were used as a basis for description of the text functions of punctuation marks and broader metagraphemic marks in the legacy of the poets of the 1960s. The analysis was carried out on the cognitive, discursive, communicative and pragmatic aspects. It is shown that the metagraphemic marks highlight those fragments in the text that bring forward or form the background knowledge which determines the direction of the reader's associative reaction to the text content. Besides the punctuation marks provide the non-linear reading of the poetical text and arrange the transition from text categories to discourse categories.
\end{abstract}

В современной лингвистике текстовая пунктуация рассматривается в герменевтическом, прагматическом, функциональном аспектах. При этом пунктуация текста описывается как целостная иерархически организованная функционально-адаптивная система, «участвующая в коммуникативно-прагматической организации текста» [Šubina 2014: 29-30] и предназначенная для реализации «ритмичности, соразмерности текстовой композиции, обеспечения единства целого и его частей» [Kol'cova 2007: 12].

Текстовая пунктуация исследуется в корреляции с авторской пунктуацией (Н.С. Валгина, Л.М. Кольцова, Н.А. Николина, Л.Н. Ткаченко и др.). Наряду с этим в современной пунктуации разграничиваются пунктуация 
предложения и пунктуация текста. В частности, в концепции Н.Л. Шубиной последняя получила название «метаграфемика». В качестве единицы метаграфемики исследователь выделяет метаграфический знак (метаграфему), под которым понимает текстовый пунктуационный знак, участвующий «в организации текста как целостной семиотической системы» [Šubina 2015: 56]. Соответственно формируется корреляция: знак препинания / метаграфический знак (метаграфема).

В поэтической речи метаграфемные, в первую очередь супраграфемные и топографемные, знаки являются средством визуализации текста. Причем в XX-XXI вв. внебуквенные графические знаки используются на разных уровнях языковой системы (от слова до предложения), что увеличивает функциональную нагруженность знака. Это позволяет нам трактовать понятие метаграфемики более широко, чем это делает Н.Л. Шубина. Метаграфемику мы рассматриваем «как единую функционально-адаптивную систему внебуквенных графических знаков, объединенных единством коммуникативнопрагматических и текстовых функций и действующих на уровне слова - высказывания - текста» [Širokova 2020: 209].

Соотношение вербального и визуального в поэтической речи активно исследуется в последние десятилетия (Р.Н. Бутов, А.В. Гірына, А.Е. Губина, Ю.В. Казарин, С.А. Кучина, А.Ж. Фаттахова и др.). При этом отмечается, что с помощью метаграфемики в поэтическом тексте формируется вторичная изобразительность, создается новая дискретность и новые связи между знаками [Fateeva 2010]. Наряду с этим метаграфемика поэтов-шестидесятников почти не рассматривалась, несмотря на то что они активно экспериментировали с пунктуацией и с другими графическими средствами визуализации текста. Цель нашей работы - рассмотреть некоторые текстовые и когнитивно-дискурсивные функции метаграфемных знаков в поэзии поэтов-шестидесятников на материале произведений Б. Ахмадулиной, А. Вознесенского, Е. Евтушенко, Р. Рождественского. Исследование осуществлялось с помощью методов полисистемного и контекстуального анализа, а также коммуникативно-прагматического метода.

Амплитуда поиска метаграфемного оформления в поэзии поэтов-шестидесятников достаточно широка: от беспунктуационных и частично пунктуационных текстов до текстов с избыточной пунктуацией и поликодовых текстов. В текстах с частичной пунктуацией на фоне отсутствия нормативных знаков препинания используются отдельные знаки (например, только тире или сочетание тире и восклицательного знака, как в стихотворениях А. Вознесенского Я сослан в себя и К нам забредал Булат). В поэтических беспунктуационных и частично пунктуационных текстах реализуется стратегия «намеренного создания и нагнетания синтаксических неоднозначностей в тексте» [Bočaver 2016: 345], которая 
предполагает принципиальную множественность интерпретаций. Такие тексты связаны с новыми принципами «оформления поэтического, причем не силлабо-тонического, текста» [Nikolina 2009: 275].

Среди текстов с избыточной пунктуацией можно выделить два типа текстов. Первый тип - это тексты с повышенной по сравнению со стилистически нейтральной речью частотностью знаков препинания, что обусловлено особенностями ритмико-мелодической организации текстов поэтов-шестидесятников. К знакам с повышенной частотностью употребления в их поэзии можно отнести точку, тире, многоточие, запятую, вопросительный и восклицательный знаки. Кроме того, активно используется топографемика - возможности расположения стихотворных строк на плоскости. Второй тип связан с использованием созданных на основе комбинации знаков препинания окказиональных комплексных знаков. К таким знакам можно отнести, например, сочетание двух выделяющих знаков у Е. Евтушенко скобок и многоточия: (......) или использование Р. Рождественским сочетания скобок, дефиса и расположения на плоскости. Причем статус комплексного знака подтверждается многократным его использованием в конкретном произведении. Так, описанный метаграфемный комплекс Р. Рождественский использует в поэме «До твоего прихода» десять раз. Другие же знаки внутри этого комплекса варьируются, например:

Люб-

(Воздуха!

Воздуха!

Самую малость бы!

лю!

$$
\text { Самую-самую...) }
$$

(Хочешь, -

Уедем куда-нибудь

заново,

замертво,

Люб-

за море?..)

(Богово - богу,

а женское - женщине

сказано, воздано.)

лю!

(Ты покоренная.

Ты непокорная...

Воздуха!

[Roždestvenskij 2017: 278-279]

Воздуха!) 
Поликодовые тексты характерны прежде всего для А. Вознесенского, который использует математические знаки (например, $+=$ ), расположение стихотворных строк в рамках, в форме рисунка, собственно рисунки, а также создает видеомы - визуальную поэзию.

Взаимодействуя с синтаксической организацией текста и типом передаваемой информации, метаграфемные знаки выступают как средство распределения разноплановой информации. Наряду с этим они обеспечивают семантическую целостность текста за счет объединения дистантно расположенных фрагментов текста в семантическую текстовую парадигму, инвариантом которой выступает тип распределенной в тексте информации: фактуально-событийная, эмотивная, связанная с разными субъектными или темпоральными планами и т.п. Например, в фрагменте из стихотворения Е. Евтушенко «Серебряный бор» знаки пунктуации организуют два целостных текста, один из которых выделен скобками и многоточиями, другой - кавычками:

(Я ждал тебя в Серебряном бору...)

«Послушай, я должна с тобой серьезно».

(... Полумальчишка и полумужчина...)

«Поговорить. Зачем нам вместе жить?»

(... Еще не смея ни на что решиться...)

«Я не люблю тебя. Ты все убил».

(... И все-таки решившийся на все.)

[Evtušenko 2019: 190]

При этом разрушенная на уровне синтагматических связей когезия компенсируется парадигматическими связями текстовых фрагментов, репрезентирующих разные субъектные сферы и маркированных разными знаками препинания.

Наиболее частотным средством распределения разноплановой информации и формирования парадигматических внутритекстовых связей в поэзии шестидесятников выступают скобки и шрифтовые выделения (как правило, курсивом). Например, в книге А. Вознесенского «Антимиры» репрезентируются смысловые оппозиции-антимиры: человек / природа, жизнь / смерть, бытовое / бытийное, физическое / ментальное. Смысловые фрагменты, связанные с разными компонентами оппозиции, сополагаются и чередуются друг с другом, их разграничение осуществляется за счет шрифтового варьирования. Поскольку шрифтовое варьирование не является, в отличие от скобок, ограничительным знаком, границы между описываемыми мирами оказываются открытыми, сглаженными.

Кроме того, метаграфемные знаки выделяют в тексте фрагменты, актуализирующие определенные фоновые знания или формирующие знания, необходимые для «запуска» ассоциативной реакции на текстовое содержание, 
тем самым обеспечивают включенность поэтического текста в поэтический дискурс и широкий культурно-исторический контекст.

Так, цитаты в поэтический текст обычно вводятся без кавычек. Поэтому редупликация пунктуационных знаков при цитации акцентирует внимание читателя на интертекстемах и выступает как сильный пунктуационный знак. Например, стихотворение А. Вознесенского «Портрет Плисецкой» разделено с помощью горизонтальных линий на восемь частей и включает пять фрагментов из лирики М. Цветаевой. Первая цитата расположена во второй части, состоящей из трех строфоидов, и выделена кавычками и количеством строк в строфоидах $(10-2-4)$. Остальные цитаты входят в третью часть. Для их выделения А. Вознесенский использует кавычки и расположение на плоскости: все четыре строфы-цитаты сдвинуты вправо, например:

В «Кармен» она впервые ступила на полную ступню.

Не на цыпочках пуантов, а сильно, плотски, человечьи.

«Полон стакан. Пуст стакан.

Гомон гитарный, луна и грязь.

Вправо и влево качнулся стан.

Князем - цыган. Цыганом - князь!»

(здесь и далее цитируется по [Voznesenskij 2018: 97-98]).

Такое метаграфемное оформление обеспечивает когерентность текстовых фрагментов внутри текста, а также текста в целом, построенного по принципу ассоциативного соположения композиционных блоков. В самом стихотворении соположение композиционных блоков, связующих личности М. Плисецкой и М. Цветаевой, подготовлено оценочно-идентифицирующим предикатом Плисеикая - Цветаева балета и вставной конструкцией Жила-была девочка - Майя ли, Марина ли - не в этом суть. При этом объединяющим компонентом выступает смысл «гениальная женщина»: А ее уже мучит дар ее - неясный самой // себе, но нешуточный. Двойное выделение цитат в сочетании с композиционным строением актуализирует интертекстуальные связи не только с поэтическим дискурсом М. Цветаевой, но и с поэтическим дискурсом шестидесятников и - шире - художественным дискурсом XX в. Последнее связано с композиционным приемом построения художественного текста на основе ассоциативного соположения композиционных блоков. При этом у знаков пунктуации, маркирующих интертекстемы и границы композиционных блоков, актуализируется объединяющая функция. По такому принципу построен, например, рассказ И. Бунина «Мистраль».

Рассмотрим, как описанные функции метаграфемных знаков взаимодействуют в поэтическом тексте на примере «Отрывка из маленькой 
поэмы о Пушкине» Б. Ахмадулиной, включающего две главы: 1. Он и она; 2. Он - ей. Первая глава состоит из восьми четверостиший и включает в себя фактуально-событийную и эмоционально-оценочную информацию о лирических героях. Причем в произведение лирические герои вводятся с помощью вопросно-ответных комплексов на основе приема композиционного параллелизма: Каков? - Таков: как в Африке, курчав и рус, как здесь, где вы и я, где север. (1-4 четверостишия). Какова она? Божественна! (5-8 четверостишия. Здесь и далее цитируется по [Ahmadulina 2019: 137-139]).

Первая композиционная часть главы, репрезентирующая личность лирического героя, организована преимущественно неполными предложениями, с незаполненными позициями субъектов-подлежащих. Причем большинство предложений являются нераспространенными, осложненными однородными предикатами, а в распространенных предложениях всего один или два распространяющих члена предложения. С помощью такого синтаксического строения осуществляется актуализация рематической информации, визуализируемой в тексте с помощью повышенной частотности точек, запятых и тире: Когда влюблен-опасен, зол в речах. // Когда весна-хмур, нездоров, рассеян. // Ужасен, если оскорблен. Ревнив. // Рожден в Москве.

В этой части в сконцентрированном виде представлена информация, апеллирующая к фоновым знаниям адресата о Пушкине и к определенным стереотипам русской лингвокультуры. Так, в тексте осуществляются многократные отсылки к африканскому происхождению поэта с помощью топонимов Африка, Нил, производных от них (нильские воды), метафорических перифраз (негр ремесла; чуждые пеклы). Этим запускается ассоциативная реакция: актуализируется переносное значение прилагательного африканский ‘необузданный, пылкий' [Tolkovyj 1935] и связанного с ним словосочетания африканские страсти 'о пылких, необузданных чувствах' [Slovar' 1991]. Ассоциация в заданном направлении поддерживается лексемами в функции оценочных предикатов опасен, зол, ужасен, ревнив, разгневан, опасный, настигнет и убъет, а также сравнением, построенным на основе текстового соположения предложений, включающих метафору, обыгрывающую полисемию глагола закипать: Истоки крови - родом из чуждых пекл, где закипает Нил. Пульс - бешеный. Куда там нильским водам! Весь этот ассоциативный ряд подготавливает читателя к восприятию содержания второй главы.

В основе композиции произведения - ассоциативное соположение текстовых частей, что позволяет соединять фрагменты с разными пространственными (Африка, Москва, Одесса) и темпоральными координатами.

Во второй части главы расширяется тип информации: к оценочнохарактеризующей и апеллятивной (отсылающей к фоновым знаниям) информации добавляется событийно-фактуальная и событийно-фабульная. 
Это приводит и к расширению используемых синтаксических конструкций и знаков препинания. Так, предложение, вводящее фабульное событие встречу лирических героев, расположено в четвертом и пятом строфоидах и разорвано двойным пробелом, выступающим сильным метаграфемным знаком:

В глазах - та странность, что белок белей, чем нужно для зрачка, который светел.

Негр ремесла, а рыщет вдоль аллей, как вольный франт. Вот так ее и встретил

в пустой аллее. Какова она?

Божественна! Он смотрит [...].

Таким образом, предложение, распределенное между двумя строфоидами, одновременно выступает скрепой двух композиционных частей главы.

Во второй композиционной части сохраняется динамизм, фрагментарность и рубленый ритм первой части, однако отсылка к менее устойчивым фоновым знаниям о поэте требует введения определенной фактуальной информации. Для этого Б. Ахмадулина использует номинативные, эллиптические и собственно неполные предложения, что сохраняет повышенную частотность точек и тире: Двадиать третий год. // Одесса. Разом - ссылка и свобода. [...] Ему - двадиать четьре года. // Звать - Каролиной.

Наряду с этим вводится информация о лирической героине с помощью эмоционально-оценочных неполных предложений: Божественна! O, из чаровниц! - и двух вставных конструкций, заключенных в скобки. Эти вставки тематически можно объединить как мужчины, влюбленные в героиню: Пушкин, муж Собаньский, граф Витт. Вставка о Пушкине (5-й строфоид) лапидарна. Она строится на лексическом повторе, связующем композиционные части главы: Когда влюблен-опасен, зол в речах. [...] Он смотрит (злой, опасный). Причем в предложении со вставкой впервые появляется замещенная с помощью личного местоимения позиция подлежащего (он - влюбленный поэт). Вторая вставка является развернутой. Она включает не только информацию о мужьях героини, но и расширяет темпоральную перспективу за счет отсылки к ее прошлому и будущему, а также за счет метакомментария Б. Ахмадулиной, организующего время читателя. Причем сама вставка распределена между тремя строфоидами, каждый из которых состоит их четырех строк (соответственно занимает строки: $3-4,1-4,1)$, тем самым с помощью топографемики рематическая информация членится по значимости:

Собаньская (Ржевуской рождена, но рано вышла замуж, муж - Собаньский,

бесхитростен, ничем не знаменит, 
тих, неказист и надобен для виду.

Его собой затмить и заменить

со временем случится графу Витту.

Об этом после). Двадцать третий год.

Вторая глава передает содержание черновика письма Пушкина к героине и репрезентирует эмоциональное состояние поэта. В эту часть входят семь вставных конструкций, включающих лексему зачеркнуто. Причем прерывистость речи автора письма, выражающая его сильные эмоции, передается не только содержанием вставок, нарушением когерентности, но и пунктуационным оформлением - сочетанием скобок и многоточия:

Я глуп (зачеркнуто)... Я так неловок

(зачеркнуто)... Я оскудел умом.

Не молод я (зачеркнуто)... Я молод,

[...] Сердцу тесно

(зачеркнуто)... Кокетство Вам к лицу

(зачеркнуто)... Вам не к лицу кокетство.

Когда я вижу Вас, я всякий раз

смешон, подавлен, неумен, но верьте

тому, что я (зачеркнуто)... что Вас,

о, как я Вас (зачеркнуто навеки)...

При этом однотипно оформленные вставки с многоточием выступают не только как эмотивы, но и являются средством формирования связности текста на фоне нарушенной когерентности. Кроме того, за счет введения в последнюю вставку темпорального показателя навеки и завершающего текст многоточия изменяется темпоральная перспектива произведения, обеспечивается включенность текста поэмы в широкий культурно-исторический контекст, происходит актуализация времени автора поэмы и его читательской аудитории.

Таким образом, метаграфемные знаки выполняют текстовые, коммуникативно-прагматические и когнитивно-дискурсивные функции. В поэзии шестидесятников они участвуют:

- в выделении в тексте определенной информации, детерминирующей ассоциативную реакцию читателя и актуализирующей в его сознании определенные фрагменты знания;

- в распределении и объединении разноплановой информации, предопределяющей нелинейное прочтение поэтического текста и неоднозначность его интерпретации, а также подготавливают переход от собственно текстовых категорий к категориям дискурса, обеспечивающим междискурсивные связи: текст - автор (поэт) - адресат (аудитория поэта). 


\section{Литература}

Ahmadulina B.A., 2019, «Po ulice moej kotoryj god...»: stihotvoreniâ i poèmy, SanktPeterburg: Azbuka, Azbuka-Attikus.

Bočaver S.Û., 2016, Nekonvencional'naâ vâznost' sovremennogo russkogo poètičeskogo teksta, Trudy instituta russkogo âzyka im. V.V. Vinogradova, 7, pp. 338-348.

Evtušenko E.A., 2019, Stihotvoreniâ, Moskva: Èksmo.

Fateeva N.A., 2010, Metagrafemika kak otraženie avangardnogo myšleniâ, Russian Literature, iss. 67, № 3-4, pp. 303-317.

Kol'cova L.M., 2007, Hudožestvennyj tekst čerez prizmu avtorskoj punktuacii, avtoreferat diss. [...] d-ra filol. nauk, Voronež: VGU.

Nikolina N.A., 2009, Aktivnye processy v âzyke sovremennoj hudožestvennoj literatury, Moskva: Gnozis.

Roždestvenskij R.I., 2017, Èho lûbvi: stihotvoreniâ, poèmy, Moskva: Izd-vo «È».

Slovar'sovremennogo russkogo literaturnogo âzyka: v 20 t., 1991, K.S. Gorbačevič (ed.), Moskva: Russkij âzyk.

Širokova E.N., 2020, Metagrafemika kak faktor smysloobrazovaniâ v poèzii Roberta Roždestvenskogo [in:] L.V. Raciburskaâ (ed.), Nacional'nye kody v âzyke i literature. Ázyk kak kul'turno-istoričeskoe dostoânie naroda, Nižnij Novgorod: NNGU im. N.I. Lobačevskogo, pp. 208-215.

Šubina N.L., 2014, Funkcii metagrafemiki v kommunikativno-pragmatičeskoj organizacii teksta, Naučnoe mnenie, 10, pp. 28-35.

Šubina N.L., 2015, Tekstovaâ punktuaciâ kak ob'ekt interpretiruûsej mysli, Naučnoe mnenie, 4, pp. 54-60.

Tolkovyj slovar' russkogo âzyka: v 4 t., 1935, D.N. Ušakov (ed.), Moskva: Sovetskaâ ènciklopediâ.

Voznesenskij A.A., 2018, Stihotvoreniâ. Poèmy, Moskva: Izd-vo «È». 